\title{
Controlling animal growth and body size - does fruit fly physiology point the way?
}

\author{
Savraj S. Grewal
}

Address: Clark Smith Brain Tumor Center, Southern Alberta Cancer Research Institute, Department of Biochemistry and Molecular Biology, University of Calgary, Alberta, T2N 1N4, Canada

Email: grewalss@ucalgary.ca

Fl000 Biology Reports 2012, 4:12 (doi:10.3410/B4-12)

This is an open-access article distributed under the terms of the Creative Commons Attribution-Non Commercial License (http://creativecommons.org/licenses/by-nc/3.0/legalcode), which permits unrestricted use, distribution, and reproduction in any medium, provided the original work is properly cited. You may not use this work for commercial purposes.

The electronic version of this article is the complete one and can be found at: http://f1000.com/reports/b/4/I2

\begin{abstract}
The question of how growth and size are controlled has fascinated generations of biologists. However, the underlying mechanisms still remain unclear. The last year or so has seen a flurry of reports on the control of growth and body size in Drosophila, and a central theme to these papers is the idea of signaling between organs as a control mechanism for overall body growth and development. While this concept is obviously not new, these fly studies now open up the possibility of using a genetically tractable system to dissect in detail how organ-to-organ communication dictates body size.
\end{abstract}

\section{Introduction}

Why are legs longer than arms? Why is a Dalmatian bigger than a Dachshund? The question of how growth and size are controlled has fascinated generations of biologists. However, the underlying mechanisms still remain unclear. In recent years, the power and versatility of Drosophila genetics, combined with some imaginative experiments by fruit fly researchers, has revealed new ideas about the control of animal growth. In particular, several recent reports have shown how organ-to-organ signaling can influence both the rate of body growth and the size of organs. In this review, I highlight some of these key papers, and I speculate on future research and on what the fly work might be telling us about mammalian physiology and growth.

\section{Growth during the Drosophila life cycle}

As they develop, Drosophila progress through three main stages of life - embryo, larva, and pupa - before emerging as adults. Virtually all the body growth occurs in the larval stage, during which animals increase in mass approximately 200-fold [1]. This mass increase is dependent on dietary protein: restriction of protein intake leads to a reduced rate of larval growth and development, while complete starvation triggers growth arrest [2,3]. Most of this nutrition-dependent increase in larval mass is contributed by an increase in the size of polyploid cells (i.e. cells containing multiple copies of the normal haploid set of chromosomes) that make up the bulk of the larval tissues, such as muscle, fat body, gut, epidermis and salivary gland. Nestled among these polyploid tissues are the brain and imaginal discs, which eventually contribute to adult structures. Communication between these different organs and tissues is emerging as an important control on the overall larval growth rate and body size, especially in response to the availability of dietary nutrients. Two key endocrine factors underlie this communication: the Drosophila insulin-like peptides, and the steroid hormone ecdysone [4]. Drosophila contains seven different Drosophila insulin-like peptides. These are expressed in different temporal and spatial patterns throughout larval and pupal development $[5,6]$. In particular, under nutrient-rich conditions, discrete neurosecretory cells within the brain express and release a subset of these Drosophila insulinlike peptides, which then circulate throughout the hemolymph (fly 'blood' or interstitial fluid) and trigger growth in target tissues by binding to the cell surface insulin receptor and activating a conserved intracellular 
PI3 (phosphoinositide-3) kinase/Akt kinase pathway [7]. In this way, endocrine Drosophila insulin-like peptide signaling couples dietary protein to larval growth. Ecdysone is produced and released from the prothoracic gland. Pulses of ecdysone secretion are responsible for controlling progression through the larval period and for triggering the onset of pupation, and, as with the Drosophila insulin-like peptides, these ecdysone effects are controlled by dietary protein and are dependent on ribosome synthesis within the prothoracic gland $[4,8,9]$. Together, the Drosophila insulin-like peptides and ecdysone regulate body size by controlling both the rate and the duration of the larval growth period. Recent studies have provided new details and insights into how this physiological and signaling network governs growth during fly development.

\section{Recent advances:}

\section{Signaling from fat to brain}

The larval fat body is a key nutrient-sensing organ that acts as a buffer between fluctuating nutrient conditions and the internal organs. For example, when larvae are deprived of dietary protein, fat body cells undergo autophagy and changes in lipid storage. These metabolic effects are essential to remobilize scarce nutrients and promote organismal survival [10,11]. In addition, the fat body functions as an important endocrine organ that can signal the fly's nutritional status to other remote tissues. Over the last decade, a series of elegant studies from the laboratory of Pierre Leopold has shown an essential role for TOR (target of rapamycin) kinase in one such endocrine function of the fat body - signaling to the brain to promote Drosophila insulin-like peptide release [12-14]. In all eukaryotes, availability of extracellular nutrients, such as amino acids and sugars, can activate the conserved TOR kinase, leading to changes in metabolism, growth and proliferation $[15,16]$. Leopold and colleagues showed that, in larvae, when dietary protein levels are high, amino acid import into fat body cells stimulates TOR kinase. This increased TOR activity then promotes the relay of a secreted signal from the fat to the brain, which controls the expression and release of three Drosophila insulin-like peptides (2, 3 and 5) from neurosecretory cells [12,14]. Thus, in this way, endocrine signaling from the fat body links nutrition to systemic insulin signaling and growth.

Two recent papers from the labs of Alex Gould and Andrea Brand have now described how fat-to-brain signaling can also trigger local endocrine responses in the brain to regulate stem cell proliferation $[17,18]$. After hatching, neural stem cells in the larval brain start proliferating upon feeding. Pioneering studies over a decade ago by Britton and Edgar showed that this nutritional response was triggered by a secreted signal from the fat to the brain [2]. The Gould and Brand labs showed that, as with the control of systemic Drosophila insulin-like peptide signaling and growth, this fat body effect on neural stem cells requires TOR activation in fat cells. In this case, however, the fat-brain signal stimulates the release of Drosophila insulin-like peptide 6 from glial cells in the brain. Drosophila insulin-like peptide 6 then acts locally to trigger neural stem cell proliferation via an insulin receptor/PI3 kinase signaling pathway. Thus, signaling from the fat to brain can promote both local proliferative responses in the brain and also trigger systemic effects on overall tissue and body growth. Together, these exciting findings raise a number of questions. First and foremost, what is the secreted signal from fat to brain, and is this signal the same in the case of both local glial Drosophila insulin-like peptide 6 release and systemic Drosophila insulin-like peptide 2, 3 and 5 release? Second, how does TOR signaling in the fat body regulate the secreted signal? Stimulation of mRNA translation has been proposed to be an important effector of TOR. So perhaps translation of either the signal (if it is a secreted peptide) or an enzyme that promotes synthesis of the signal may be modulated. Indeed, a recent report showed that simply increasing the levels of the initiator tRNA ( $\mathrm{tRNA}_{\mathrm{i}}{ }^{\mathrm{Met}}$ ) in the fat body was sufficient to enhance systemic insulin signaling and promote an increase in development and body size [19]. Importantly, these effects were associated with increased mRNA translation and could be reversed by genetic suppression of translational capacity. Finally, what is the target of the fat signal? Certainly both glial and neurosecretory cells can respond to the signal to promote Drosophila insulin-like peptide release. But are these cells direct targets or does the signal impinge upon other cells to activate a neural network that ultimately promotes Drosophila insulin-like peptide release? In the case of the neurosecretory cells, the neurotransmitters GABA and serotonin, and the neuropeptides Neuropeptide $F$ and Tachykinin-related peptide are all reported to be required for Drosophila insulin-like peptide production [20-22], but whether these are actually modulated by nutrition/fat body signaling remains to be determined.

\section{Signaling from muscle}

The emerging picture from the above studies is that signaling from fat can influence function in another remote tissue. Recent work from Demontis and Perrimon also showed a similar 'remote control' function for muscle [23]. They reported that nutrient-dependent PI3 kinase signaling was required to control growth and development of larval body wall muscle. Interestingly, they also showed that inhibition of PI3 kinase in these developing larval muscles also suppressed growth in other tissues and inhibited overall body growth and size. These non-autonomous effects on body size were due to effects on larval feeding behavior following inhibition of PI3 kinase signaling in 
muscle. Whether these effects require a secreted musclederived factor, or whether they also rely on control of systemic Drosophila insulin-like peptide signaling is unclear.

\section{Signaling from imaginal discs}

The imaginal discs are organs consisting of mitotic cells that grow and divide during the larval period. The discs eventually undergo metamorphosis into adult structures, such as the eyes, wings, legs and thorax, during the pupal stage. Damage to the larval discs induces cell death and growth arrest, followed by a period of compensatory proliferation and growth to allow for regeneration of the damaged tissue [24]. Importantly, developing Drosophila larvae are able to sense this damage and, as a result, larval development is prolonged, and growth of other tissues is slowed while the regeneration occurs. This phenomenon provides an example of coordination of growth between organs to ensure proper body size and proportion. Two recent papers shed light on mechanisms underlying this coordination $[25,26]$. Parker and Shingleton showed that, when growth is genetically suppressed in just the wing disc, other discs and tissues show a corresponding slowing of growth and overall larval development is delayed. They suggested that this slowing of growth was due to reduced ecdysone signaling as a result of growth retardation in the prothoracic gland [26]. Similarly, Halme et al. reported that radiation-induced disc damage also delayed larval growth through a non-autonomous effect on ecdysone production and release from the prothoracic gland. In this case, the defect in ecdysone signaling was due to reduced synthesis of prothoracicotropic hormone (PTTH), a neuropeptide responsible for promoting ecdysone release. Furthermore, using a genetic screen, Halme et al. identified a prominent role for retinoid biosynthesis in the signaling pathway that links tissue damage to delayed larval development [25]. Again, as with both the muscle and fat body, the nature of the signal emanating from growth impaired or damaged discs is unclear. The identification of a role for retinoids does provide a clue, although it is unclear whether normal retinoid synthesis is required in the damaged discs or target tissues in order for proper 'delay development' signals. Imaginal discs express a variety of morphogens and secreted factors essential for organ growth, e.g. Dpp, $\mathrm{Wg}$, Hh and Egf. Moreover, the expression of several of these is upregulated following tissue damage, raising the possibility that they may be involved in signaling to other tissues to delay growth and development [27].

\section{Signaling from gut bacteria: another 'organ' in growth control?}

It has been long appreciated that, in all animals, the gut is home for large numbers of commensal bacteria [28].
Indeed, humans contain more bacterial cells within their gut than human cells throughout their body. These bacterial populations play an important role in controlling host homeostasis and metabolism. Two recent papers have identified these gut bacteria as essential components of the control systems that govern body development and growth in Drosophila [29,30]. Strikingly, both studies reported that depletion of gut bacteria led to delayed growth and smaller body size, particularly when dietary protein was limiting. In each report, the species of bacteria that appeared to play the dominant role on host growth differed, as did the range of bacteria found in the fly gut. Nevertheless, in both cases, the major influence of the gut bacteria was to promote host insulin signaling. In particular, the presence of gut bacteria appeared to augment the organ-organ signaling networks that promote Drosophila insulin-like peptide and ecdysone release. These findings suggest the intriguing notion that gut bacteria act as another 'organ' that can signal to larval tissues to promote both organismal growth and development, but what underlies this 'signaling' is unclear. However, Shin et al. were able to show that gut bacteria deficient in acetic acid metabolism were deficient in the ability to promote growth and development, and that supplementation of a bacteria-free diet with acetic acid could partially restore normal growth and development [29]. Given the presence of commensal bacteria in the guts of all metazoans, it is interesting to speculate whether they also play a similar role in controlling growth and size in other animals.

\section{Brain sparing during nutrient restriction}

Nutrient deprivation inhibits cell growth in the bulk of the tissues that make up the larvae, such as gut, fat, muscle and epidermis [2]. However, an intriguing recent study from Gould and colleagues has shown that, in contrast to these organs, growth of the larval brain is protected from starvation [31]. These workers found that neural progenitor cells in the brain were insensitive to inhibition of both Inr and TOR - two essential mediators of nutrientdependent signaling in other larval cells. Instead, Gould and colleagues identified an alternative signaling pathway involving the receptor tyrosine kinase Alk (anaplastic lymphoma kinase) that functions to control brain growth. Importantly, the ligand for Alk, Jelly-Belly, is constitutively secreted from glial cells. Thus, even when starvation suppresses the levels of systemic Drosophila insulin-like peptides and inhibits growth in the majority of larval tissues, local Jelly Belly-Alk signaling between glia and neural cells within the brain can maintain brain growth and size. These brain-sparing effects rely on the ability of Alk signaling to bypass the requirement for insulin receptor and TOR and independently regulate their key downstream effectors, such as PI3 kinase and 4EBP. Alk is 
a conserved kinase that is highly expressed in the mammalian CNS and overexpressed in certain brain tumors [32]. Hence, it is interesting to speculate as to whether these 'brain sparing' effects seen in Drosophila may explain the role of Alk signaling in the mammalian brain.

\section{Future directions}

The last year or so has seen a flurry of reports on the control of growth and body size in Drosophila. A central theme to these papers is the idea of signaling between organs as a control mechanism for overall body growth and development (see Figure 1 for summary). This concept is obviously not new; decades of research on the growth hormone/insulin-like growth factor axis in mammals have emphasized the role of endocrine factors in body growth. But these fly studies now open up the possibility of using a genetically tractable system to dissect in detail how organ-to-organ communication dictates body size. For example, one obvious question that these papers leave unanswered concerns the nature of the relevant organ-to-organ signaling molecules. Undoubtedly, the versatility and sophistication of Drosophila genetics, and in particular the ability to perform targeted,

Figure I. Signaling between different organs can influence overall growth and development in Drosophila larvae

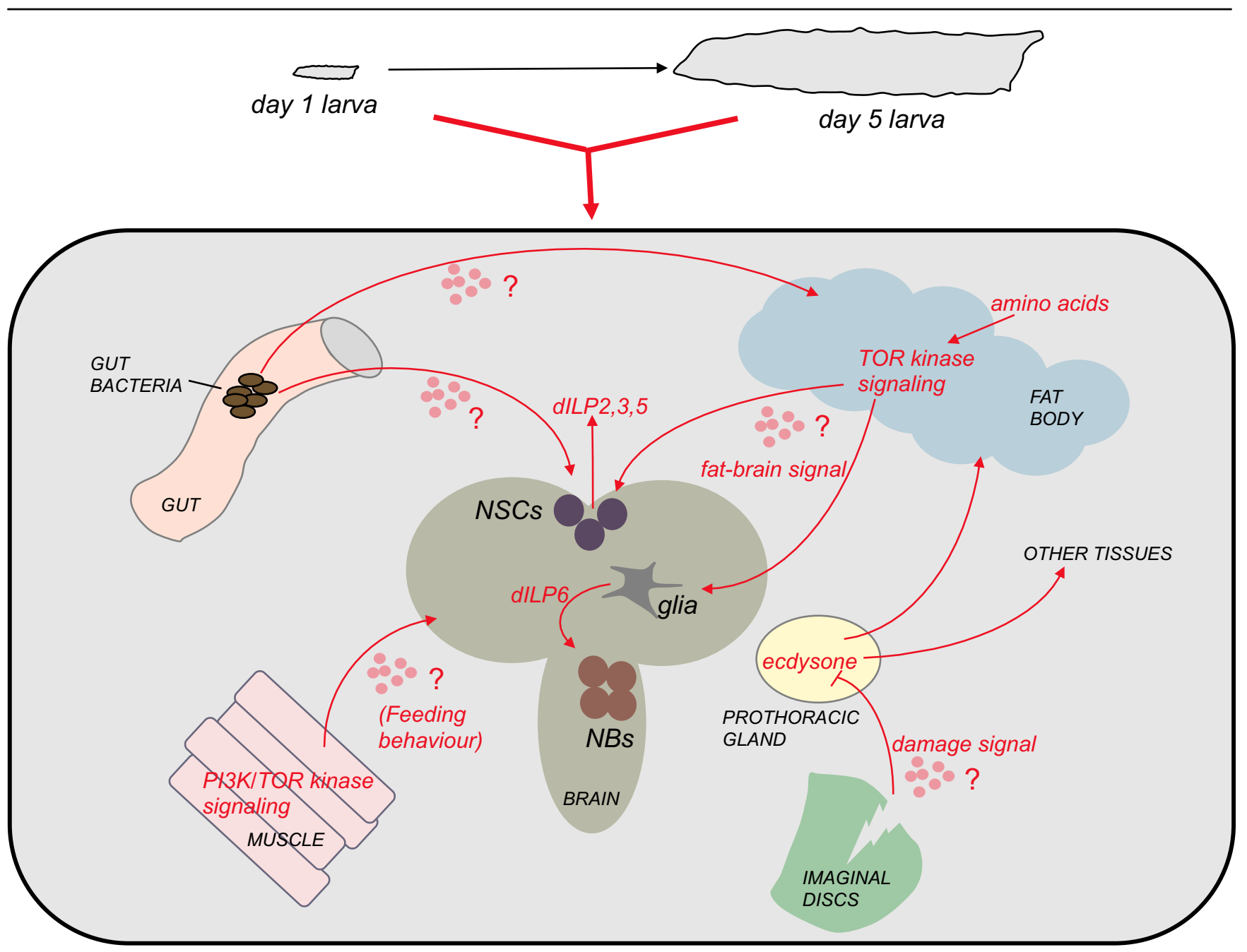

(TOP) Over a period of 4-5 days, Drosophila larvae progress through development and increase in mass approximately 200 -fold. This growth and development is triggered and maintained by the availability of dietary protein. (BOTTOM) Recent studies have described how communication between different larval tissues can influence overall body growth and development (see text for details). In many cases, the nature of both the secreted factors that mediate this inter-organ signaling is still unclear. Abbreviations: dILP, Drosophila insulin-like peptides; NB, neuroblast; NSC, neurosecretory cell; PI3, phosphoinositide-3; TOR, target of rapamycin. 
tissue-specific loss-of-function RNAi screens, will spur research into the identification of these elusive factors. Once we discover these secreted factors, will we find that they are conserved, and might they play similar endocrine roles in other animals? Certainly, the insulin-like peptides present a strong precedent for conserved organ-to-organ signaling networks that control body growth and size. Nevertheless, even if the factors are not conserved, the principle of organ-to-organ signaling and physiology as governing mechanisms for body size control will probably be central to animal development. And no doubt Drosophila research will continue to lead the way in unraveling these mechanisms.

\section{Abbreviations}

Alk, anaplastic lymphoma kinase; PI3, phosphoinositide-3; PTTH, prothoracicotropic hormone; TOR, target of rapamycin.

\section{Competing interests}

The author declares he has no competing interests.

\section{References}

I. Robertson FW: The ecological genetics of growth in Drosophila. 6. The genetic correlation between the duration of the larval period and body size in relation to larval diet. Genet Res 1963, 4:74-92.

2. Britton JS, Edgar BA: Environmental control of the cell cycle in Drosophila: nutrition activates mitotic and endoreplicative cells by distinct mechanisms. Development 1998, 125:2 149-58.

FI000 Factor 6

Evaluated by Savraj Grewal 17 May 2012

3. Britton JS, Lockwood WK, Li L, Cohen SM, Edgar BA: Drosophila's insulin/PI3-kinase pathway coordinates cellular metabolism with nutritional conditions. Dev Cell 2002, 2:239-49.

FI000 Factor 6

Evaluated by Ernst Hafen 15 Apr 2002

4. Tennessen JM, Thummel CS: Coordinating growth and maturation insights from Drosophila. Curr Biol 20I I, 2 I:R750-7.

5. Brogiolo W, Stocker H, lkeya T, Rintelen F, Fernandez R, Hafen E: An evolutionarily conserved function of the Drosophila insulin receptor and insulin-like peptides in growth control. Curr Biol 200I, II:2I3-2I.

6. Ikeya T, Galic M, Belawat P, Nairz K, Hafen E: Nutrient-dependent expression of insulin-like peptides from neuroendocrine cells in the CNS contributes to growth regulation in Drosophila. Curr Biol 2002, I 2:1293-300.

\section{FI000 Factor 6}

Evaluated by Laura Johnston 28 Aug 2002

7. Teleman AA: Molecular mechanisms of metabolic regulation by insulin in Drosophila. Biochem J 2009, 425:13-26.

8. Layalle S, Arquier N, Leopold P: The TOR pathway couples nutrition and developmental timing in Drosophila. Dev Cell 2008, 15:568-77.

FI000 Factor 7

Evaluated by Iswar Hariharan 25 Nov 2008, Savraj Grewal I7 May 2012
9. Lin JI, Mitchell NC, Kalcina M, Tchoubrieva E, Stewart MJ, Marygold S], Walker CD, Thomas G, Leevers SJ, Pearson RB, Quinn LM, Hannan RD: Drosophila ribosomal protein mutants control tissue growth non-autonomously via effects on the prothoracic gland and ecdysone. PLoS Genet 201 I, 7:e 1002408.

FI000 Factor 9

Evaluated by Sheila McCormick 05 Jan 2012, Savraj Grewal 09 Feb 2012

10. Baker KD, Thummel CS: Diabetic larvae and obese fliesemerging studies of metabolism in Drosophila. Cell Metab 2007, 6:257-66.

II. Scott RC, Schuldiner O, Neufeld TP: Role and regulation of starvation-induced autophagy in the Drosophila fat body. Dev Cell 2004, 7:167-78.

FI000 Factor 9

Evaluated by Daniel Klionsky 16 Aug 2004, Sally Leevers 03 Sep 2004

12. Geminard C, Rulifson EJ, Leopold P: Remote control of insulin secretion by fat cells in Drosophila. Cell Metab 2009, 10:199-207.

FI000 Factor 6

Evaluated by Savraj Grewal 17 May 2012

13. Delanoue R, Slaidina M, Leopold P: The steroid hormone ecdysone controls systemic growth by repressing dMyc function in Drosophila fat cells. Dev Cell 2010, 18:1012-21.

FI000 Factor 6

Evaluated by Savraj Grewal 17 May 2012

14. Colombani J, Raisin S, Pantalacci S, Radimerski T, Montagne J, Leopold P: A nutrient sensor mechanism controls Drosophila growth. Cell 2003, II 4:739-49.

FI000 Factor 18

Evaluated by Sally Leevers 26 Sep 2003, Peter Taylor 02 Oct 2003, Michael Hall 09 Oct 2003, Peter Gallant 13 Oct 2003, Ken Irvine 12 Nov 2003, Savraj Grewal 17 May 2012

15. Wullschleger $\mathrm{S}$, Loewith $\mathrm{R}$, Hall MN: TOR signaling in growth and metabolism. Cell 2006, 124:47I-84.

16. Kim J, Guan KL: Amino acid signaling in TOR activation. Annu Rev Biochem 2011, 80:1001-32.

17. Sousa-Nunes R, Yee LL, Gould AP: Fat cells reactivate quiescent neuroblasts via TOR and glial insulin relays in Drosophila. Nature 20II, 47 I:508-12.

FI000 Factor 13

Evaluated by Genevieve Rougon 14 Mar 201I, Yuh-Nung Jan and jill Wildonger 25 Mar 201I, Savraj Grewal 17 May 2012

18. Chell JM, Brand AH: Nutrition-responsive glia control exit of neural stem cells from quiescence. Cell 201 I, 143:1 I6I-73.

FI000 Factor 9

Evaluated by Aurelio Teleman and Katrin Hahn 27 Jan 20I I, Savraj Grewal 17 May 2012

19. Rideout EJ, Marshall L, Grewal SS: Drosophila RNA polymerase III repressor Mafl controls body size and developmental timing by modulating tRNAiMet synthesis and systemic insulin signaling. Proc Natl Acad Sci U S A 2012, 109: I 139-44.

FI000 Factor 8

Evaluated by Joost Zomerdijk and Sarah Goodfellow 06 Mar 2012

20. Luo J, Becnel J, Nichols CD, Nassel DR: Insulin-producing cells in the brain of adult Drosophila are regulated by the serotonin 5-HT(IA) receptor. Cell Mol Life Sci 20II, 69:47I-84.

21. Enell LE, Kapan N, Soderberg JA, Kahsai L, Nassel DR: Insulin signaling, lifespan and stress resistance are modulated by metabotropic GABA receptors on insulin producing cells in the brain of Drosophila. PLOS One 20II, 5:eI5780. 
22. Birse RT, Soderberg JA, Luo J, Winther AM, Nassel DR: Regulation of insulin-producing cells in the adult Drosophila brain via the tachykinin peptide receptor DTKR. J Exp Biol 20II, 214:420I-8.

23. Demontis F, Perrimon N: Integration of Insulin receptor/Foxo signaling and dMyc activity during muscle growth regulates body size in Drosophila. Development 2009, 136:983-93.

24. Simpson $P$, Berreur $P$, Berreur-Bonnenfant $J$ : The initiation of pupariation in Drosophila: dependence on growth of the imaginal discs. J Embryol Exp Morphol 1980, 57:155-65.

25. Halme A, Cheng M, Hariharan IK: Retinoids regulate a developmental checkpoint for tissue regeneration in Drosophila. Curr Biol 20II, 20:458-63.

FI000 Factor 9

Evaluated by Duojia Pan 30 Mar 2010, Malcolm Maden 09 Jul 2010

26. Parker NF, Shingleton AW: The coordination of growth among Drosophila organs in response to localized growth-perturbation. Dev Biol 20II, 357:3।8-25.

27. Repiso A, Bergantinos $C$, Corominas $M$, Serras F: Tissue repair and regeneration in Drosophila imaginal discs. Dev Growth Differ 20II, 53:177-85.

28. Hooper LV, Gordon Jl: Commensal host-bacterial relationships in the gut. Science 200I, 292: III5-8.

29. Shin SC, Kim SH, You H, Kim B, Kim AC, Lee KA, Yoon JH, Ryu JH, Lee W]: Drosophila microbiome modulates host developmental and metabolic homeostasis via insulin signaling. Science 20II, 334:670-4.

FI000 Factor 18

Evaluated by Andrew Gewirtz and Matam Vijay-Kumar 15 Nov 20II, Pankaj Kapahi 09 Dec 20II, Craig Montell and Youngseok Lee 04 Jan 2012, Andrew S Neish 16 Mar 2012, Richard Daneman and Fabien Sohet 18 Mar 2012, Savraj Grewal 17 May 2012

30. Storelli G, Defaye A, Erkosar B, Hols P, Royet J, Leulier F: Lactobacillus plantarum promotes Drosophila systemic growth by modulating hormonal signals through TORdependent nutrient sensing. Cell Metab 20II, 14:403-14.

FI000 Factor 7

Evaluated by Andrew S Neish 0I Dec 20II, Savraj Grewal 17 May 2012

31. Cheng LY, Bailey AP, Leevers SJ, Ragan TJ, Driscoll PC, Gould AP: Anaplastic lymphoma kinase spares organ growth during nutrient restriction in Drosophila. Cell 20II, 146:435-47.

FI000 Factor 15

Evaluated by Michele Pagano and Shafi Kuchay 10 Aug 201I, Aurelio Teleman and Constantinos Demetriades 26 Sep 201I, Joseph Avruch and Angela Papageorgiou 06 Feb 2012, Savraj Grewal 17 May 2012

32. Iwahara T, Fujimoto J, Wen D, Cupples R, Bucay N, Arakawa T, Mori S, Ratzkin B, Yamamoto T: Molecular characterization of ALK, a receptor tyrosine kinase expressed specifically in the nervous system. Oncogene 1997, 14:439-49. 